\title{
Effect of Weather on Cryptocurrency Index: Evidences From Coinbase Index
}

\author{
Chinnadurai Kathiravan ${ }^{1}$, Murugesan Selvam ${ }^{1}$, Balasundram Maniam ${ }^{2}$, Sankaran Venkateswar ${ }^{3}$, J. Gayathri $^{1}$ \& \\ Amrutha Pavithran ${ }^{1}$ \\ ${ }^{1}$ Department of Commerce and Financial studies, Bharathidasan University, Tiruchirappalli, India \\ ${ }^{2}$ Sam Houston State University, Texas, USA \\ ${ }^{3}$ School of Economics and Business Administration, Saint Mary's College of California, USA \\ Correspondence: Chinnadurai Kathiravan, Ph.D Research Scholar in Management (Full Time), Department of \\ Commerce and Financial studies, Bharathidasan University, Tiruchirappalli, India.
}

Received: July 1, 2019

doi:10.5430/ijfr.v10n4p108
Accepted: July 17, 2019

Online Published: July 21, 2019

URL: https://doi.org/10.5430/ijfr.v10n4p108

\begin{abstract}
This study proposes to investigate the dynamic relationships between the three weather factors (temperature, humidity, and wind speed) in New York City of USA and Coinbase Index from Federal Reserve Bank of St. Louis, in the USA. Statistical tools like Descriptive Statistics, Unit Root, Granger Causality Test and Johansen Co-Integration test were employed. This study clearly found that the temperature influenced the investors' mood and their investment decision in respect of Cryptocurrency index (Coinbase Index) and also found that there was long run equilibrium between the sample variables during the study period. The results of study provided strong evidence against the Efficient Market Hypothesis (EMH).
\end{abstract}

Keywords: cryptocurrency, weather effect, risk, volatility, ARCH, GARCH, Bitcoin

JEL: G12, G14

\section{Introduction}

Digi Cash, the first digital currency, was introduced in the $19^{\text {th }}$ Century (Chaum, 1981; Phillip A., 2017). Nakamoto (2008), improved concept of peer-to-peer networking and crowd sourcing and it was introduced as new digital cash format called the Bitcoin. Cryptocurrencies have emerged as a growing digital currency, introduced into a new investment segments (Brauneis A. and Mestel R., 2018; Urquhart, 2016). The number of Cryptocurrencies like Bitcoins has been reached more than 1,500 (Kim, 2017). More than 500 Cryptocurrencies did have a market capitalization, worth over 25 million dollars (Tomás and Ibañez, 2018). Cryptocurrencies are now accepted as legal tender in many developed and developing nations and also accepted by different financial institutions, including banks, hedge funds and even Government bodies (Vidal-Tomás and Ibañez, 2018). The most popular segment of Cryptocurrencies, in the form of market capitalization, was the Bitcoin (Brauneis A., Mestel R., 2018). The market capitalization of Bitcoin had reached 10.1 to 79.7 billion from October 2016 to October 2017 (M. Brandvold et al., 2015) the price of Bitcoin also has increased from 616 to 4800 US dollars (Shaen Corbet et al 2017). Bitcoin developed as the largest decentralized Cryptocurrency, with the help of block chain technology (Bariviera, 2017). Therefore, many academic researchers have started to conduct intensive research on Bitcoin (Dyhrberg, 2016; Katsiampa, 2017; Urquhart, 2016 and Kim, 2017). No wonder cryptocurrencies have become the most trending topics in recent economic and financial issues and, they have been discussed by several bodies like European Central Bank, European Banking Authority and Financial Action Task Force, businesses and academic communities (Dwyer, 2015; Bariviera et al., 2017). Besides, were many financial scholars attempted to analyze the suitability of cryptocurrencies as investment assets and found some statistical significance such as market efficiency (Urquhart, (2016); Bariviera, 2017); Nadarajah and Chu, 2017), leptokurtosis (Chan et al., 2017), heteroschedasticity, long-memory (Phillip et al., 2018), return-volume relationships (Gkillas and Katsiampa, 2018). 
According to Figure 1, four different psychological biases, namely, overconfidence, conservatism, herding attitude and availability directly influenced the investors' decision-making process and this has been proved in the developed nations at different periods of time.

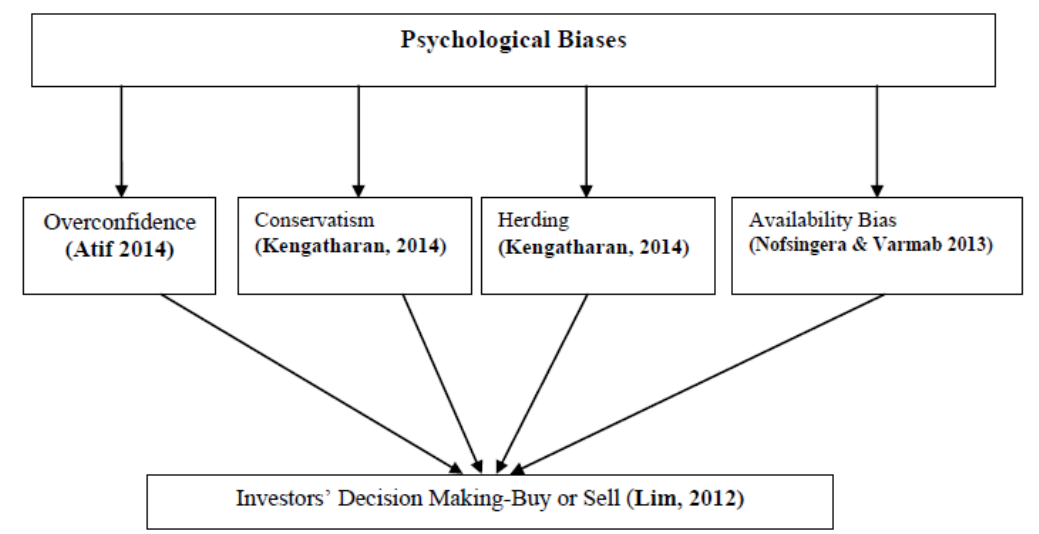

Figure 1. The psychological biases on investors' decision making process

Source: Developed by authors from the model of Suzaida Bakar and Amelia Ng Chui Yi (2016)

Majority academic research studies, conducted so far, have focused only on time series based on technical aspects of cryptocurrency markets. But there was a lack of comprehensive research, on behavioral aspects of the investors, with different cryptocurrencies in respect of weather factors. To fill this gap, this study examines the dynamic relationship between Cryptocurrency index, namely Coinbase Index and three different weather factors (temperature, humidity, and wind speed) in New York City. This is the first study of this nature that addresses the behavioral aspects of investors covering two variables-weather factors (namely temperature, humidity, and wind speed) and cryptocurrency.

Thus this study contributes to the existing body of literature. The study was structured as follows; in Section 2, the study discusses the data source and the methodology, the Section 3 discusses the empirical findings and concludes with Section 4.

\subsection{Objectives of the Study}

The aim of the study is to find out the cause and effect relationship and long run equilibrium relationship between weather factors (temperature, humidity, and wind speed) in New York City of USA and Coinbase Index from Federal Reserve Bank of St. Louis

\subsection{Hypotheses of the Study}

- NH1-There is no normal distribution among the Coinbase Index and weather factors in New York City

- NH2-There is no stationarity among the Coinbase Index and weather factors in New York City

- $\quad$ NH3-There is no volatility among the Coinbase Index and weather factors in New York City

- NH4-There is no cause and effect relationship between the Coinbase Index and weather factors in New York City

- NH5-There is no long run equilibrium relationship between the Coinbase Index and weather factors in New York City

\section{Research Methodology}

\subsection{Sample Selection}

In order to analyse the dynamic relationships between weather factors and Coinbase Index, the study used three weather factors (temperature, humidity, and wind speed) in New York City of USA and cryptocurrency data, namely, Coinbase Index from of Federal Reserve Economic Data (FRED) database of Federal Reserve Bank of St. Louis. 


\subsection{Study Period}

The present study covered a period of three years from 01.01.2015 to 30.06.2018. The Coinbase index was introduced in USA from January 1, 2015 (https://am.coinbase.com/index)

\subsection{Data Sources}

For the purpose of examining the relationship between weather factors and Coinbase Index, the daily closing values of sample index and weather factors were collected from two different databases. The data relating to Cryptocurrency (Coinbase Index) were collected from Federal Reserve Economic Data (FRED) database (https://fred.stlouisfed.org/series/CBCCIND) of Federal Reserve Bank of St. Louis. The data relating to New York City daily weather factors (temperature, humidity, and wind speed) were obtained from the National Climatic Data Center (https://www.ncdc.noaa.gov/cdo-web/), in Asheville, North Carolina. The missing values in the data on sample variables, for some days, were filled up by taking the average of the two nearest cases. The formula of calculating the natural log of closing prices is given below.

$$
\mathrm{R}_{\mathrm{t}}=\ln \left(\mathrm{p}_{\mathrm{t}} / \mathrm{p}_{\mathrm{t}-1}\right)
$$

Where:

$\mathrm{R}_{\mathrm{t}}$ : Return on day ' $\mathrm{t}$ '

$\mathrm{P}_{\mathrm{t}}$ : Index Closing Value on day ' $\mathrm{t}-1$ '

1n: Natural log

\subsection{Tools Used for Analysis}

The following tools were used for the purpose of analysis.

- Descriptive Statistics (to find out the normality of Cryptocurrency index and Weather Factors)

- Unit Root Test (to test stationarity of Cryptocurrency index and Weather Factors).

- $\quad$ ARCH and GARCH models (to examine the impact of Cryptocurrency index and Weather Factors)

- Granger Causality (to examine the cause and effect of Cryptocurrency index and Weather Factors), and

- Johansen Co-Integration (to find out long run relationship of Cryptocurrency index and Weather Factors)

\section{Empirical Results}

This section describes the relationship between weather factors on Cryptocurrency index by using Descriptive Statistics, Unit Root Test, ARCH \& GARCH model, Unrestricted Cointegration Rank Test, and Granger Causality test, as follows.
a. Normality for the Returns of Cryptocurrency Index and Weather Factors in New York City of USA.
b. Stationarity for the Returns of Cryptocurrency Index and Weather Factors in New York City of USA.
c. Volatility for the Returns of Sample Cryptocurrency index and Weather Factors in New York City of USA.
d. Granger Causality for the Returns of Cryptocurrency Index and Weather Factors in New York City of USA, and

e. Johansen Co-Integration for the Returns of Cryptocurrency Index and Weather Factors in New York City of USA.

\subsection{Normality for the Returns of Cryptocurrency Index and Weather Factors in New York City of USA}

The results of descriptive statistics, for the returns of Cryptocurrency index, namely, Coinbase Index and three different weather factors (temperature, humidity, and wind speed) in New York City of USA, during the study period from 01.01.2015 to 30.06.2018, are presented in Table 1. The mean and medium values of sample Cryptocurrency index returns were at0.003574and 0.002336 respectively. But the values of kurtosis (51.99629) and skewness (1.999222) clearly showed that the distribution of index returns was normal during the study period. Also the Jarque-Bera values further supported the fact that the returns data of Cryptocurrency index recorded a normal distribution during the study period. As far as the weather factors was concerned, wind speed of New York City scored the highest mean value (0.097461) but temperature of New York City attained the lowest mean value $(-0.102817)$, during the study period. The analysis of standard deviation (SD) showed that temperature of New York City scored the highest SD Value (3.234021) and this indicated the fact that temperature in New York City was an important indicator for knowing the risk (high) relating to Coinbase Index but humidity of New York City attained 
the lowest risk value in terms of standard deviation (SD) of 0.307323 . The analysis values of skewness, kurtosis and the Jarque- Bera tests also clearly indicated that the distribution of return data for temperature, humidity, and wind speed was normal during the study period. Hence the null hypothesis (NH01) - "There is no normality in the daily return data of Cryptocurrency index and weather factors in New York City over the sample period", was rejected.

Table 1. Results of descriptive statistics of cryptocurrency index and weather factors in New York City of USA from 1st January 2015 to $30^{\text {th }}$ June 2018

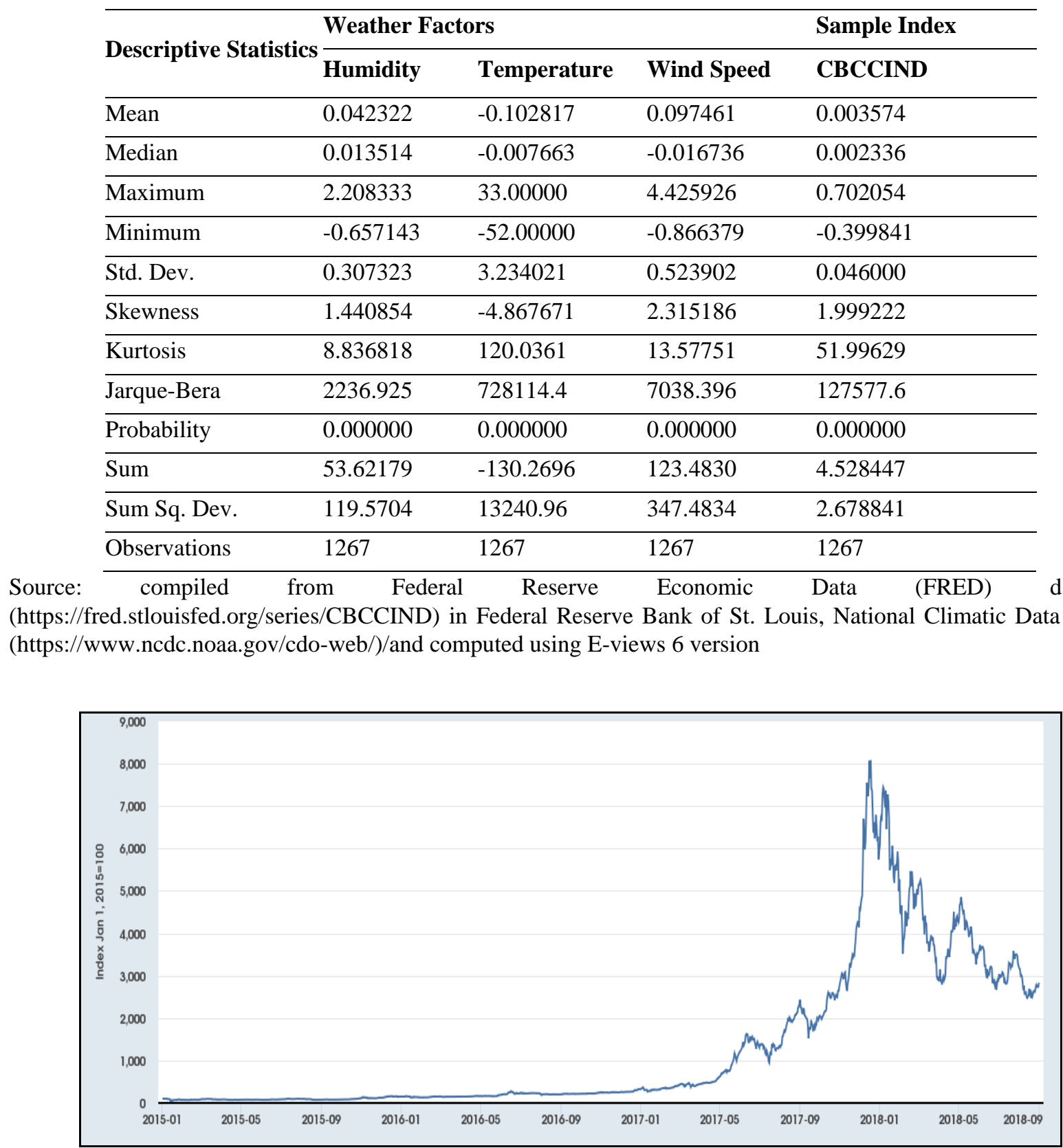

Figure 2. Movements of daily closing value for the cryptocurrency index from 1st January 2015 to $30^{\text {th }}$ June 2018 Source: https://fred.stlouisfed.org/series/CBCCIND\#0 


\subsection{Stationarity for the Returns of Cryptocurrency Index and Weather Factors in New York City of USA}

Table 2 shows the results regarding the stationarity for the sample Cryptocurrency index, namely, Coinbase Index and three different weather factors (temperature, humidity, and wind speed) in New York City of USA, during the study period from 01.01.2015 to 30.06.2018. Augmented Dickey Fuller Test (ADF) of Said and Dickey (1984), Phillips Perron Test (PP)] of Phillips and Perron (1988) and KPSS tests of Kwiatkowski et al. (1992) were used to test the stationarity of Coinbase Index and weather factors. Besides, the sample Cryptocurrency index, namely, Coinbase Index and three different weather factors were analyzed under test critical values at significant levels of $1 \%$, $5 \%$ and $10 \%$. The analysis of the Table shows that the probability values ( $\mathrm{P}$ values) for Cryptocurrency index and three weather factors in New York City were nearby zero (0.0000 to 0.0001), under three tools, namely, ADF, Phillips Perron Test and KPSS tests used for the analysis. The statistical values of sample variables were less than that of test critical values at $1 \%, 5 \%$ and $10 \%$ level of significance. In other words, there was stationarity of the returns data of sample Cryptocurrency index, namely, Coinbase Index and three different weather factors (temperature, humidity, and wind speed) in New York City during the study period. Hence the Null Hypothesis (NH2) - There is no stationarity among the Cryptocurrency index and weather factors in New York City, was rejected.

Table 2. The results of unite root test for the returns of sample index and weather factors in the sample city in USA from 1st January 2015 to $30^{\text {th }}$ June 2018

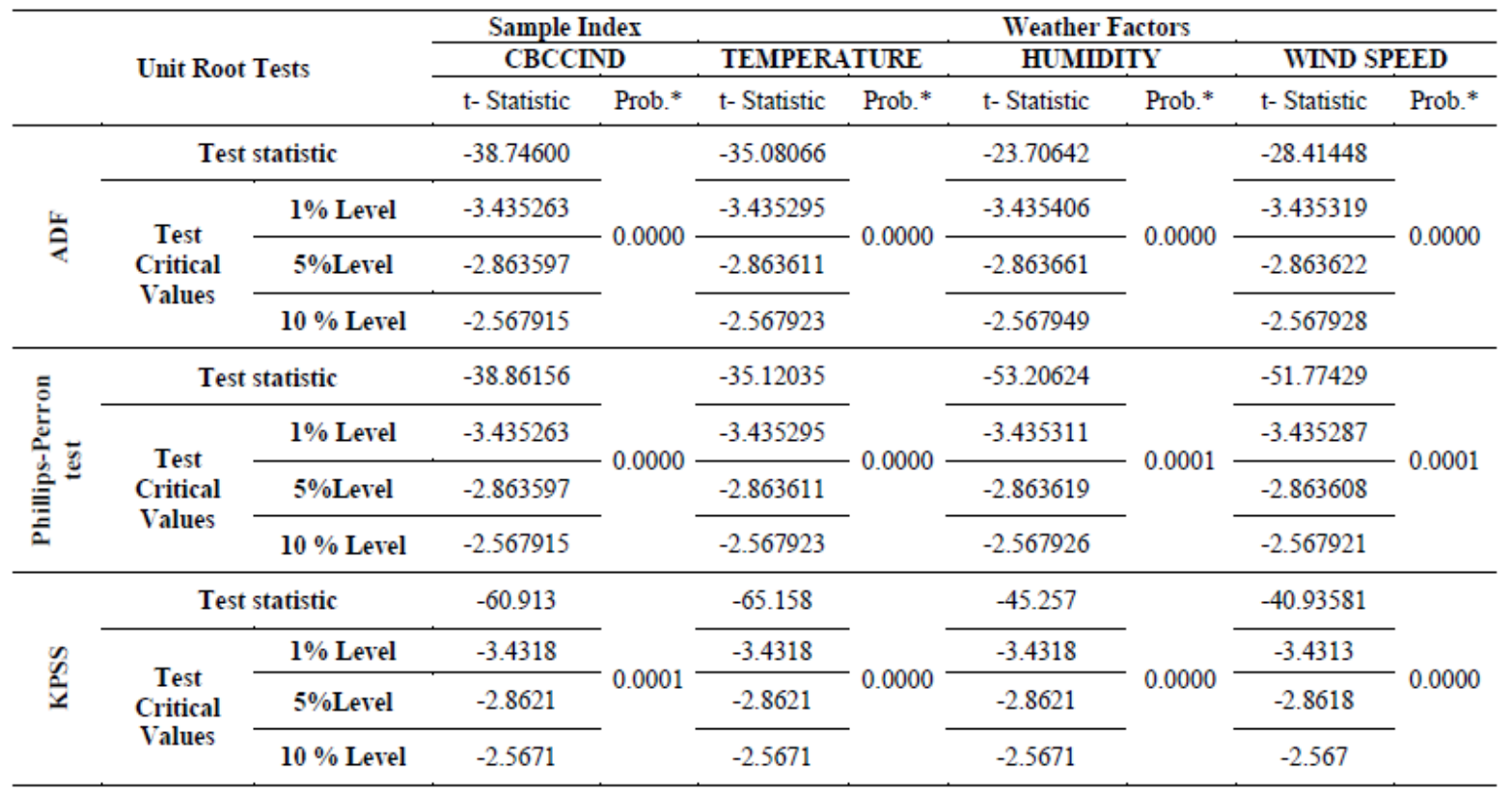

Sources: compiled from Federal Reserve Economic Data (FRED) database (https://fred.stlouisfed.org/series/CBCCIND) in Federal Reserve Bank of St. Louis, National Climatic Data Center (https://www.ncdc.noaa.gov/cdo-web/)/and computed using E-views 6 version

Note: Critical Value at $1 \%, 5 \%$, and $10 \%$ level of significant

\subsection{Volatility for the Returns of Sample Cryptocurrency Index and Weather Factors in New York City of USA}

Table 3 reveals the results of volatility (using autoregressive conditional heteroskedastic (ARCH) and generalized autoregressive conditional heteroskedastic $(\mathrm{GARCH})$ of mean equation and variance equation), for sample Cryptocurrency index, namely, Coinbase Index and three different weather factors (temperature, humidity, and wind speed) in New York City of USA during the study period from 01.01.2015 to 30.06.2018. It is clear from the table that the p-values, under mean equation for three weather factors (temperature, humidity, and wind speed) were at $0.295,0.794$ and 0.616 in New York City of USA and this indicated that the weather factors did not induce the returns of Cryptocurrency index during the study period. On the other hand, the values of variance equation of 
coefficient for sample weather factors were at 0.035 for temperature, 0.701 for humidity and 0.728 for wind speed. It is noted from the values of variance equation of coefficient that $\mathrm{p}$. values $(0.035)$ for temperature were significant. It is clear that the temperature influenced the Cryptocurrency index return volatility. In other words, all the weather variables, except temperature, namely, humidity, and wind speed were not statistically significant. It means that these two variable did not influence the return of Cryptocurrency index. Hence, the Null Hypothesis (NH3) -There is no volatility among the Cryptocurrency index and weather factors in New York City, was partially rejected.

Table 3. The results of ARCH and GARCH showing impact of weather factors in the New York City of USA on the returns of sample index from 1st January 2015 to 30th June 2018

\begin{tabular}{ccccccc}
\hline \multicolumn{7}{c}{ Mean Equation } \\
\hline $\begin{array}{c}\text { Sample/ } \\
\text { Parameters }\end{array}$ & \multicolumn{2}{c}{ TEMPERATURE } & \multicolumn{2}{c}{ HUMIDITY } & \multicolumn{2}{c}{ WIND SPEED } \\
\cline { 2 - 8 } & Co efficient & p-value & Co efficient & p-value & Co efficient & p-value \\
\hline Constant & 0.057 & 0.059 & 0.059 & 0.056 & 0.059 & 0.056 \\
\hline Weather & -0.023 & 0.295 & -0.011 & 0.794 & 0.042 & 0.616 \\
\hline & \multicolumn{7}{c}{ Variance Equation } \\
\hline Constant & 0.021 & 0.001 & 0.020 & 0.001 & 0.020 & 0.001 \\
\hline Weather & -0.079 & $\mathbf{0 . 0 3 5}$ & 0.015 & 0.701 & 0.020 & 0.728 \\
\hline ARCH & 0.109 & 0.000 & 0.112 & 0.000 & 0.108 & 0.000 \\
\hline GARCH & 0.795 & 0.000 & 0.696 & 0.000 & 0.594 & 0.000 \\
\hline
\end{tabular}

Sources: compiled from Federal Reserve Economic Data (FRED) database (https://fred.stlouisfed.org/series/CBCCIND) in Federal Reserve Bank of St. Louis, National Climatic Data Center (https://www.ncdc.noaa.gov/cdo-web/)/and computed using E-views-7 version

Note: Significant level at $>0.05$

\subsection{Granger Causality for the Returns of Sample Cryptocurrency Index and Weather Factors in New York City of USA}

The results of Granger Causality for the returns of Cryptocurrency index (namely Coinbase Index) and three different weather factors (temperature, humidity, and wind speed) in New York City of USA, during the study period from 01.01.2015 to 30.06.2018, are displayed in Table 4. The study generally accepted the null hypothesis when the p-Values for sample variables were above 0.05 and rejected same when the values were less than 0.05 , under the Granger Causality Test. The study clearly found bidirectional causal relationship between Coinbase Index and temperature in New York City (i.e. P-Value was at 0.0021 for Coinbase Index and 0.0005 for temperature) during the study period. In other words, no one weather variable, except temperature, did show statistically significant relationship during the study period. Hence the Null Hypothesis (NH03) - "There is no causal relationship between CBCCIND index and temperature in New York City", was partially accepted.

Table 4. Granger causality for the returns of CBCCIND index and weather factors in the New York City in USA from 1st January 2015 to $30^{\text {th }}$ June 2018

\begin{tabular}{lllll}
\hline Null Hypothesis: & Obs & F-Statistic & Prob. & Results \\
\hline CBCCIND does not Granger Cause Humidity & \multirow{2}{*}{1255} & 0.0877 & 0.9160 & Accepted \\
\hline Humidity does not Granger Cause CBCCIND & & 0.3412 & 0.7110 & Accepted \\
\hline
\end{tabular}




\begin{tabular}{lllll}
\hline Temperature does not Granger Cause CBCCIND & \multirow{2}{*}{1260} & 0.0733 & $\mathbf{0 . 0 0 2 1}$ & Rejected \\
\cline { 3 - 5 } CBCCIND does not Granger Cause Temperature & 0.0036 & $\mathbf{0 . 0 0 0 5}$ & Rejected \\
\hline CBCCIND does not Granger Cause Wind Speed & 0.30516 & 0.7371 & Accepted \\
\cline { 4 - 5 } Wind Speed does not Granger Cause CBCCIND & 0.67969 & 0.5070 & Accepted \\
\hline
\end{tabular}

Sources: compiled from $\quad$ Federal $\quad$ Reserve Economic Data (FRED) database
(https://fred.stlouisfed.org/series/CBCCIND) in Federal Reserve Bank of St. Louis, National Climatic Data Center (https://www.ncdc.noaa.gov/cdo-web/)/and computed using E-views 6 version

Note: Rejection of Null Hypothesis when the Probability value is less than or equal to 0.05

3.5 Johansen Co-integration for the Returns of Sample Cryptocurrency Index and Weather Factors in New York City of USA

Tables 5 show the results of Johansen Co-Integration Test for the returns of sample Cryptocurrency index, namely Coinbase Index and three different weather factors (temperature, humidity, and wind speed) in New York City of USA during the study period from 01.01.2015 to 30.06.2018. It is to be noted that the returns data of the sample Cryptocurrency index and weather factors were used to test the Co-Integration among the above samples. It is found from the results of Johansen Co-Integration Test that the Coinbase index returns was integrated with weather factors in New York City of USA. Besides, the p-Value under trace statistics and maximum Eigen values for sample variables, were below the significant levels (below 0.05 level). This indicated that there was long run equilibrium relationship or Co-Integration relationship between the returns of sample Cryptocurrency index, namely Coinbase Index and three different weather factors (temperature, humidity, and wind speed) in New York City of USA during the study period. Hence NH4- There is no long run equilibrium relationship between the Coinbase Index and weather factors in New York City was rejected.

Table 5. Unrestricted cointegration rank test (Trace) for the returns of CBCCIND index and weather factors in the New York City in USA from 1st January 2015 to $30^{\text {th }}$ June 2018

\begin{tabular}{lllll}
\hline Hypothesized No. of CE(s) & Eigenvalue & Trace Statistic & 0.05Critical Value & Prob.** \\
\hline None $*$ & 0.310995 & 1245.013 & 47.85613 & 0.0001 \\
\hline At most $1 *$ & 0.226203 & 783.8499 & 29.79707 & 0.0001 \\
\hline At most $2 *$ & 0.174365 & 466.3705 & 15.49471 & 0.0001 \\
\hline At most $3 *$ & 0.168988 & 229.1667 & 3.841466 & 0.0000
\end{tabular}

Sources: compiled from Federal Reserve Economic Data (FRED) database
(https://fred.stlouisfed.org/series/CBCCIND) in Federal Reserve Bank of St. Louis, National Climatic Data Center (https://www.ncdc.noaa.gov/cdo-web/)/and computed using E-views 6 version

Trace test indicates no Cointegration at the 0.05 level; * denotes rejection of the hypothesis at the 0.05 level; **MacKinnon-Haug-Michelis (1999) p-values

\subsection{Graphical Exposition}

The Dot Plot, drawn for the results of the weather factors (temperature, humidity, and wind speed) in New York City, USA and Coinbase Index from Federal Reserve Bank of St. Louis, over the period of study from 1st January 2015 to 30th June 2018was exhibited In Figures 3 and 4. It is observed from the Figure 3 that temperature would have spread over the whole area of New York City than other two weather variables, namely, humidity, and wind speed. It means that temperature would have strongly influenced the human attitude and their day to day activities in respect of their investment during the study period. It is clearly evident from the Figure 4 that the Coinbase Index (CBCCIND) also gradually moved in the upward direction. This indicated that the performance of Coinbase Index was better and provided higher returns to the investors during the later part of the study period. 
The movement of scatter (regression line) of weather factors (temperature, humidity, and wind speed) in New York City, USA and Coinbase Index from Federal Reserve Bank of St. Louis, over the period of study from 1st January 2015 to 30th June 2018 is shown in Figure 5. It is clear that regression lines of all the sample variables moved in the upward direction, showing positive sign and these variables did have a strong linear relationship. This shows the fact that there was interrelationship between weather factors and Coinbase Index but one variable, namely, temperature alone influenced the returns through the study period.

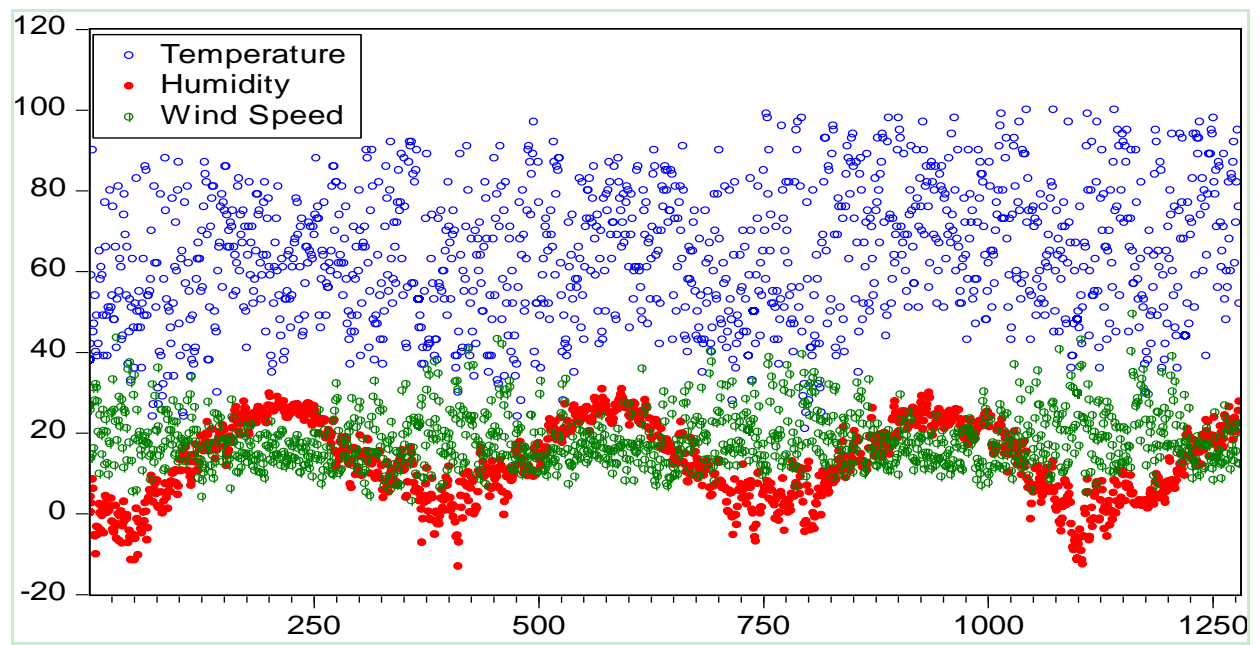

Figure 3. Dot plot results for the returns of three weather factors (temperature, humidity and wind speed) from 1st January 2015 to 30th June 2018

Source: Compiled from Federal Reserve Economic Data (FRED) database (https://fred.stlouisfed.org/series/CBCCIND) in Federal Reserve Bank of St. Louis, National

Climatic Data Center (https://www.ncdc.noaa.gov/cdo-web/)/and computed using E-views 7 version

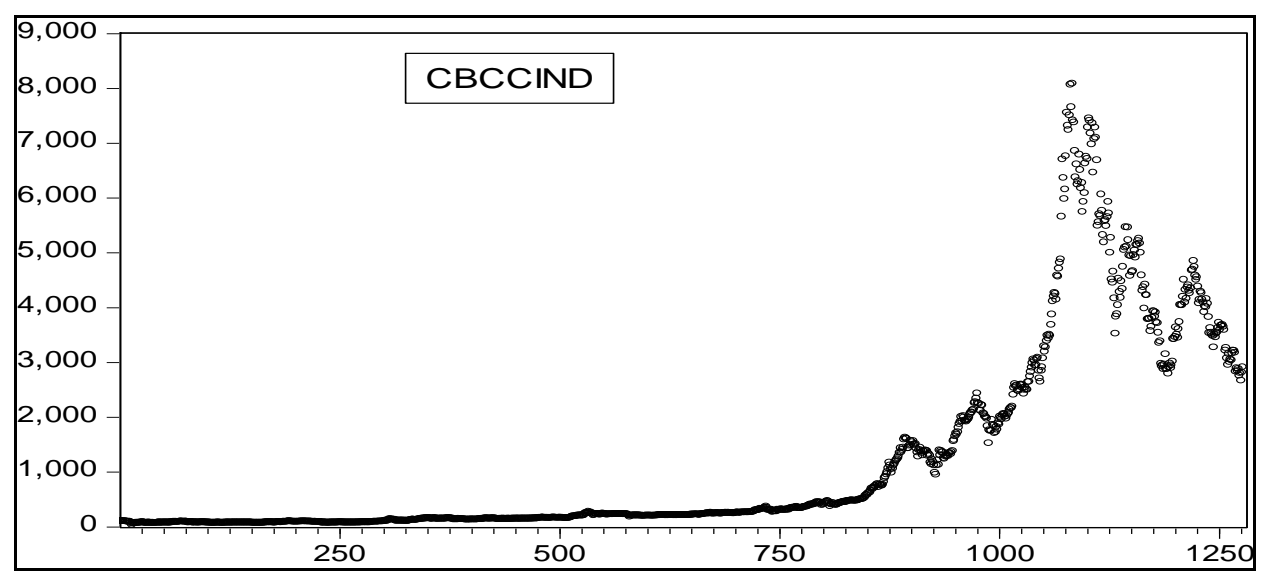

Figure 4. Dot plot for the returns of returns of CBCCIND index from 1st January 2015 to 30th

June 2018

Source: Compiled from Federal Reserve Economic Data (FRED) database (https://fred.stlouisfed.org/series/CBCCIND) in Federal Reserve Bank of St. Louis, National

Climatic Data Center (https://www.ncdc.noaa.gov/cdo-web/)/and computed using E-views 7 version 


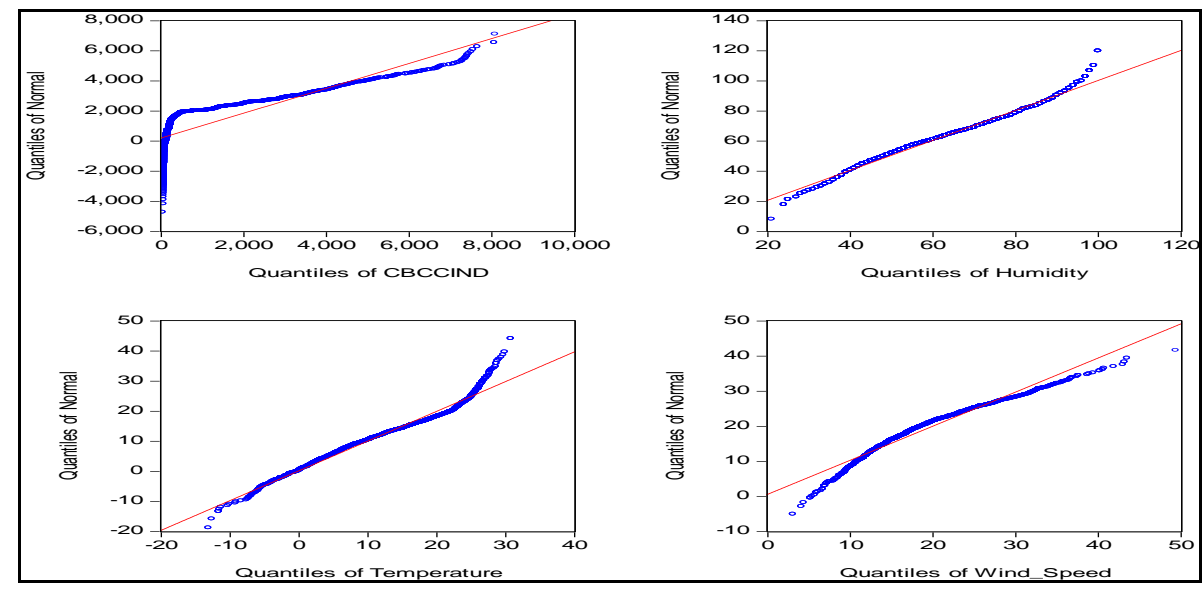

Figure 5. Scatter (regression line) for the returns of returns of CBCCIND index and weather factors (temperature, humidity and wind speed) from 1st January 2015 to 30th June 2018

Source: Compiled from Federal Reserve Economic Data (FRED) database (https://fred.stlouisfed.org/series/CBCCIND) in Federal Reserve Bank of St. Louis, National

Climatic Data Center (https://www.ncdc.noaa.gov/cdo-web/)/and computed using E-views 7 version

\section{Conclusion}

It is evident that weather factors could influence the moods of investors and their behaviors, which would, in turn, help them to take investment decisions in their life (Kathiravan et al., 2017 \& 2018). The present study, which attempted to understand the dynamic relationships between three weather factors (temperature, humidity, and wind speed) in New York City of USA and Coinbase Index from Federal Reserve Bank of St. Louis in United States, found that the temperature in New York City influenced the Cryptocurrency index negatively (from their p-value of 0.0021 and 0.0005 respectively). The study also found long run equilibrium with the Cryptocurrency index and sample weather factors. The findings of the present study confirmed the findings of previous studies of Howarth \& Hoffman 1984; Kramer \& Runde 1997; Kamstra, et al. 2000; Pardo \& Valor 2003; and Tufan \& Hamarat 2004, who found that the mood of individual investors and their consequent investment decisions were influenced by different weather factors. In short, there was chain linking between temperature levels and, human mood, their behavior and investment decisions and index returns.

\section{References}

Bakara, S., \& Yi, A. N. C. (2016). The Impact of Psychological Factors on Investors' Decision Making in Malaysian Stock Market: A Case of Klang Valley and Pahang. Procedia Economics and Finance, 35, 319-328. https://doi.org/10.1016/S2212-5671(16)00040-X

Bariviera, A. (2017). The inefficiency of bitcoin revisited: A dynamic approach. Economics Letters, 161, 1-4. https://doi.org/10.1016/j.econlet.2017.09.013

Brandvold, M., Molnár, P., Vagstad, K., \& Valstad, O. C. A. (2015). Price discovery on Bitcoin exchanges. Int. Fin. Markets, Inst. and Money, 36, 18-35. https://doi.org/10.1016/j.intfin.2015.02.010

Brauneis, A., \& Mestel, R. (2018). Price discovery of cryptocurrencies: Bitcoin and beyond. Economic Letters, 165, 58-61. https://doi.org/10.1016/j.econlet.2018.02.001

Chan, S., Chu, J., Nadarajah, S., \& Osterrieder, J. (2017). A statistical analysis of cryptocurrencies. Risk Financ. Manage, 10(12), 1-23. https://doi.org/10.3390/jrfm10020012

Chaum, D. L. (1981). Untraceable electronic mail, return addresses, and digital pseudonyms. Commun ACM, 24(2), 84-90. https://doi.org/10.1145/358549.358563

Corbet, S., Meegan, A., Larkin, C., Lucey, B., \& Yarovaya, L. (2018). Exploring the dynamic relationships between cryptocurrencies and other financial assets. Economics Letters. https://doi.org/10.1016/j.econlet.2018.01.004

Dwyer, G. (2015). The economics of bitcoin and similar private digital currencies. Journal of Financial Stability, 17, 81-91. https://doi.org/10.1016/j.jfs.2014.11.006 
Dyhrberg, A. (2016). Bitcoin, gold and the dollar - a garch volatility analysis. Finance Research Letters, 16, 85-92. https://doi.org/10.1016/j.frl.2015.10.008

Dyhrberg, A. (2016). Hedging capabilities of bitcoin. Is it the virtual gold?. Finance Research Letters, 16, 139-144. https://doi.org/10.1016/j.frl.2015.10.025

Gkillas, K., \& Katsiampa, P. (2018). An application of extreme value theory to cryptocurrencies. Economic Lett., 164, 109-111. https://doi.org/10.1016/j.econlet.2018.01.020

Howarth, E., \& Hoffman, M. S. (1984). A multidimensional approach to the relationship between mood and weather, British Journal of Psychology, 75(1), 15-23. https://doi.org/10.1111/j.2044-8295.1984.tb02785.x

Kafayat, A. (2014). Interrelationship of Biases: Effect Investment Decisions Ultimately. Theoretical and Applied Economics, XXI 6(595), 85-110.

Kamstra, M. J., Kramer, L. A., \& Levi, M. D. (2000). Losing sleep at the market: The daylight-savings anomaly. American Economic Review, 90(4), 1005-1011. https://doi.org/10.1257/aer.90.4.1005

Kathiravan, C., Raja, M., \& Chinnadorai, K. M. (2018). Stock Market Returns and the Weather Effect in Sri Lanka. SMART Journal of Business Management Studies, 14(2).

Kathiravan, C., Selvam, M., Kannaiah, D., Lingaraja, K., \& Thanikachalam, V. (2018). On the relationship between weather and Agricultural Commodity Index in India: a study with reference to Dhaanya of NCDEX. Quality \& Quantity. https://doi.org/10.5958/2321-2012.2018.00019.2

Kathiravan, C., Selvam, M., Venkateswar, S., Lingaraja, K., \& Oli, S. M. (2017). Effect of temperature on stock market indices: A study on BSE and NSE in India. International Journal of Economic Research, 14(18), 171-181. https://doi.org/10.1007/s11135-018-0782-x

Kathiravan, C., Selvam, M., Venkateswar, S., Lingaraja, K., Vasani, S. A., \& Kannaiah, D. (2018). An empirical investigation of the inter-linkages of stock returns and the weather at the Indian stock exchange. Academy of Strategic Management Journal, 17(1).

Katsiampa, P. (2017). Volatility estimation for bitcoin: A comparison of garch models. Economics Letters, 158, 3-6. https://doi.org/10.1016/j.econlet.2017.06.023

Kengatharan, L., \& Kengatharan, N. (2014). The Influence of Behavioral Factors in Making Investment Decisions and Performance: Study on Investors of Colombo Stock Exchange, Sri Lanka. Asian Journal of Finance \& Accounting, 6(1), 1-23. https://doi.org/10.5296/ajfa.v6i1.4893

Kim, T. (2017). On the transaction cost of Bitcoin. Financ. Res. Lett., 23, 300-305. https://doi.org/10.1016/j.frl.2017.07.014

Kramer, W., \& Runde, R. (1997). Stocks and the weather: An exercise in data mining or yet another capital market anomaly?. Empirical Economics, 22, 637-641. https://doi.org/10.1007/BF01205784

Kwiatkowski, D., Phillips, P. C., Schmidt, P., \& Shin, Y. (1992). Testing the null hypothesis of stationarity against the alternative of a unit root: How sure are we that economic time series have a unit root? Journal of Econometrics, 54(1-3), 159-178. https://doi.org/10.1016/0304-4076(92)90104-Y

Lim, L. C. (2012). The Relationship between Psychological Biases and the Decision Making of Investor in Malaysian Share Market. Unpublished Paper, International Conference on Management, Economics \& Finance (ICMEF 2012) Proceeding.

Nadarajah, S., \& Chu, J. (2017). On the inefficiency of Bitcoin. Economic Lett., 150, 6-9. https://doi.org/10.1016/j.econlet.2016.10.033

Nakamoto, S. (2008). Bitcoin: A peer-to-peer electronic cash system. Retrieved from www.bitcoin.org

Nofsingera, J. R., \& Varmab, A. (2013). Availability, Recency and Sophistication in the Repurchasing Behavior of Retail Investors. Journal of Banking \& Finance, 37(7), 2572-2585. https://doi.org/10.1016/j.jbankfin.2013.02.023

Pardo, A., \& Valor, E. (2003). Spanish stock returns: Rational or weather-influenced?. European Financial Management, 9(1), 117-126. https://doi.org/10.1111/1468-036X.00210

Phillip, A., Chan, J., \& Peiris, S. (2017). A new look at Cryptocurrencies. Economics Letters. https://doi.org/10.1016/j.econlet.2017.11.020 
Phillip, A., Chan, J., \& Peiris, S. (2018). On long memory effects in the volatility measure of Cryptocurrencies. Financ. Res. Lett. https://doi.org/10.1016/j.frl.2018.04.003

Phillips, P. C., \& Perron, P. (1988). Testing for a unit root in time series regression. Biometrika, 75(2), 335-346. https://doi.org/10.1093/biomet/75.2.335

Said, S. E., \& Dickey, D. A. (1984). Testing for unit roots in autoregressive-moving average models of unknown order. Biometrika, 71(3), 599-607. https://doi.org/10.1093/biomet/71.3.599

Sigo, M. O., Selvam, M., Maniam, B., Kannaiah, D., Kathiravan, C., \& Thanikachalam, V. (2018). Big data analytics-application of artificial neural network in forecasting stock price trends in India. Academy of Accounting and Financial Studies Journal, 22(3).

Sigo, M. O., Selvam, M., Venkateswar, S., Lingaraja, K., Amirdhavasani, S., \& Kathiravan, C. (2018). Predicting stock market movements of India using data deterministic approach. Academy of Strategic Management Journal, $17(2)$.

Tufan, E., \& Hamarat, B. (2004). Do cloudy days affect stock exchange returns: Evidence from Istanbul stock exchange. Journal of Naval Science and Engineering, 2(1), 117-126.

Urquhart, A. (2016). The inrefficiency of bitcoin. Economics Letters, 148, 80-82. https://doi.org/10.1016/j.econlet.2016.09.019

Vidal-Tomás, D., \& Ibañez, A. (2018). Semi-strong efficiency of Bitcoin. Financ. Res. Lett. https://doi.org/10.1016/j.frl.2018.03.013 